
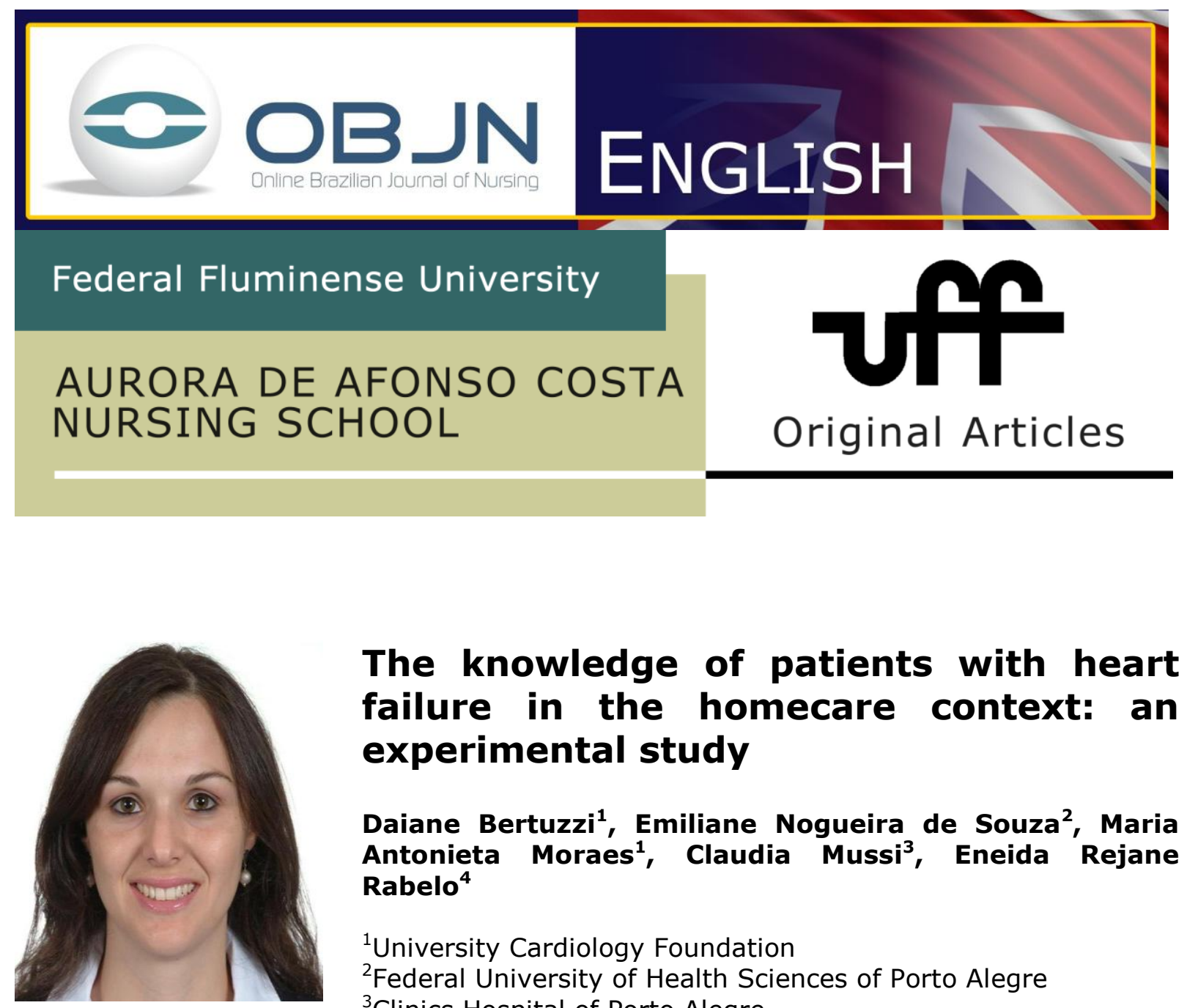

\title{
The knowledge of patients with heart failure in the homecare context: an experimental study
}

\author{
Daiane Bertuzzi ${ }^{1}$, Emiliane Nogueira de Souza ${ }^{2}$, Maria \\ Antonieta Moraes ${ }^{1}$, Claudia Mussi ${ }^{3}$, Eneida Rejane \\ Rabelo ${ }^{4}$ \\ ${ }^{1}$ University Cardiology Foundation \\ ${ }^{2}$ Federal University of Health Sciences of Porto Alegre \\ ${ }^{3}$ Clinics Hospital of Porto Alegre \\ ${ }^{4}$ Federal University of Rio Grande do Sul
}

\begin{abstract}
Aim: To assess the knowledge about the disease and their self-care of patients with heart failure (IC) before and after monitoring nursing care at home. Method: A before and after experimental study was performed with patients who were hospitalized for IC decompensation. Two home visits (VD) were undertaken after hospital discharge by specialist nurses at an interval of 30 days. 14 question quiz testing knowledge of heart disease and self-care, validated for use in Brazil, was used. The educational intervention was based on guidelines about IC. It was considered that an appropriate level of knowledge existed in those patients who had at least $70 \%$ correct on the quiz. Results: 41 patients were included, $21(51.2 \%)$ of whom were men. The whole group had an average age of $64 \pm 13.7$ years. The correct answer scores were $64 \%$ in VD1 and $70.9 \%$ in VD2 $(P=0.020)$. Discussion: Nursing interventions benefit patients by improving their knowledge. Conclusion: There was a significant improvement in terms of knowledge of heart disease and self-care after the homecare interventions.
\end{abstract}

Keywords: Heart Failure; Knowledge; Home Visit; Nurses 


\section{INTRODUCTION}

The treatment of heart failure (IC) involves the optimization of drugs with a proven impact on morbidity and mortality ${ }^{(1)}$. In addition to pharmacological treatment, measures related to adherence to medication and changes in lifestyle related to self-care, such as daily weighing, vaccination, physical activity, early recognition of the signs and symptoms of decompensation, among others, bring proven benefits ${ }^{(2)}$.

Successful treatment depends on patient compliance in terms of the need to change behaviors and lifestyles. For this it is necessary that the patient has an adequate knowledge about the pathology, signs and symptoms of decompensation and the necessary treatment, in order to prevent hospitalization and to improve the quality of life $^{(3)}$. Numerous intervention methods can assist the patient with IC, such as ambulatory consultations, home visits, and telephone contact with medical staff, among others.

Although there are many strategies, it is observed that patients with IC still face difficulties and encounter barriers to learning about their health condition. In a study involving patients with IC, it was found that the main barriers to learning about the disease were the cognitive aspects: difficulties in understanding the numerous medications, lack of awareness of the symptoms of decompensation, advanced age and low levels of literacy ${ }^{(4)}$.

It is believed that knowledge on the part of the patient about IC increases the sense of personal control and facilitates adaptation to the chronic state of the disease and to treatment. The success of this educational process should be discussed in the context of the patient, so that aspects such as socioeconomic status, education, occupation and health beliefs are considered. The strategy of sensitive listening, implemented in nursing consultations, show that the nurse can better understand the needs which may be unspoken by the client ${ }^{(5)}$.

Accordingly, the home follow-up of the patient after discharge, is a strategy that facilitates the management of patients and that of their family in a real environment ${ }^{(6)}$, in terms of improving knowledge about treatment and thus contributing to their adherence. 
This study aims to assess the knowledge of patients with IC with regard to the disease and to their self-care, before and after the monitoring of nursing care at home.

\section{METHOD}

\section{Type of Study}

This is a before and after type of experimental study, nested in a randomized clinical trial, aimed at assessing the impact of home care on the part of nursing staff, among IC patients over a period of six months after discharge.

This study was conducted with patients with a confirmed diagnosis of IC, hospitalized for a decompensation of the disease, in two hospitals in the metropolitan area of Porto Alegre, RS. The patients were located from an active search of clinical inpatient units and clinical records, and then consecutively recruited in clinical and emergency inpatient units between April 2010 and January 2011.

The verification of knowledge and educational intervention occurred in the patient's home, after discharge, on two home visits (VD) undertaken by a specialist nurse in cardiology. The 1st VD occurred between 4 and 7 days after hospital discharge, while the 2nd VD occurred between 14 and 16 days after the 1st VD.

Patients of both genders, aged 18 years or above, diagnosed with IC with systolic dysfunction (ejection fraction $\leq 45 \%$ ) of any etiology, hospitalized for decompensate disease, and who agreed to participate, were included in this research. We excluded patients with communication barriers and those with chronic degenerative neurological diseases, as well as patients who had presented with acute coronary syndrome in the last six months before randomization, patients with renal/liver/lung or systemic diseases so as not to confuse the interpretation of the findings or resulting in limited life expectancy, those on surgical or therapeutic plans that could influence the research findings and pregnant women. Also excluded were patients who had no interest in receiving home visits or who had no possibility of making telephone contact. 


\section{Monitoring of Nursing Homecare}

The monitoring of nursing homecare, performed by specialist nurses includes clinical assessment of patients with IC in terms of such aspects as etiology, the early recognition of signs and symptoms; the desired effects and side effects of medications, doses and schedules of reinforcement of prescription drugs; water and salt restriction; abstaining from cigarettes and alcohol restriction and preventive measures such as immunization and physical activity ${ }^{(7)}$.

\section{Data Collection}

During hospitalization, after the invitation to participate in the study and the acceptance on the part of the patient, socio-demographic and clinical data registered in the patients' medical records were collected. After hospital discharge, patient data such as telephone contact numbers and the date and time of the VDs were added.

To evaluate the results, we used the Disease Knowledge and Self-care Questionnaire, validated for use in $\mathrm{Brazil}^{(8)}$. This questionnaire includes questions related to diet (one question), liquids and weight (three questions), general information with regard to IC (two questions), medication (five questions), physical activity (one question), measures that improve IC (one question) and reasons for readmission (one question), totaling 14 questions. The percentage of knowledge was determined by summing the number of correct responses. The maximum score, 14 hits, corresponded to a percentage of knowledge about IC of $100 \%$. The authors consider an appropriate knowledge level to exist when the patient obtained at least $70 \%$ of the correct answers ${ }^{(8)}$.

During the first home visit (VD1), we applied the tool to check the patient's baseline knowledge and, after the nurse specialist had undertaken the nursing intervention. During the second home visit (VD2) we verified the patient's knowledge about IC.

This study was approved by the Ethics Committees of both institutions involved (Institute of Cardiology - University Cardiology Foundation and the Clinics Hospital of Porto Alegre), under numbers 4334/09 and 09-911, respectively. All participants read and signed the consent form, in duplicate. 


\section{Statistical Analysis}

After statistical analysis, we assessed the level of knowledge about IC. After VD2 this was $80 \%$, which indicated a $6.9 \%$ increase in the average percentage of knowledge compared with VD1 (effect magnitude), DP $=18.2, \mathrm{DP}=16.9$. Continuous variables were described in terms of average and standard deviation $(m \pm d p)$. The categorical variables were described in terms of absolute numbers $(n)$ and relative numbers (\%). The knowledge score following each VD was compared by using a paired t test and the McNemar test. To assess the association between the change in the average percentage of knowledge acquired and time to IC and education (years of schooling) Spearman's correlation $(P<0.05)$ was used. The SPPS v.14 statistical program was used for these analyzes.

\section{RESULTS}

Of the 41 patients included in decompensated IC who received the intervention in the form of two nursing home visiting, $51.2 \%$ were male. The whole group had an average age of $64 \pm 13.7$ years. The median of monthly family income was 1140 (635-1500) reals. $58.5 \%$ were married and $70.7 \%$ lived with their family. Other data are shown in Table 1.

Table 1. Socio-demographic and clinical characteristics of the sample $(n=41)$. Porto Alegre RS, 2011.

\begin{tabular}{lr}
\hline Variables & $\mathbf{n ( \% )}$ \\
\hline Age (years)* & $64.0 \pm 13.7$ \\
Gender (male) & $21(51.2)$ \\
Caucasian & $27(65.9)$ \\
Schooling (years) & $6.3 \pm 3.8$ \\
Occupation (retired) & $30(73.2)$ \\
Ejection fraction of the left ventricle (\%)* & $29.5 \pm 7.3$
\end{tabular}


Functional class (New York Heart Association)

II

$14(34.1)$

III

$21(51.2)$

IV

Etiology

Ischemic

Idiophatic

Hypertensive

IC time (years) ${ }^{\dagger}$

Comorbities

Hypertension

Acute coronary syndrome

Diabetes mellitus

Systolic blood pressure $(\mathrm{mmHg})^{*}$

$110.2 \pm 18.1$

Diastolic blood pressure $(\mathrm{mmHg})^{*}$

$69.9 \pm 10.8$

Continuous use of medications

Furosemide

Beta-blockers

Inhibitors of angiotensin converting enzyme

Digoxin

Spironolactone

$22(53.7)$

$* \overline{\text { Data }}$ presented as average \pm standard deviation; ${ }^{\dagger}$ Data presented median (25 percentile; 75 percentile).

Regarding the previous admissions, $51.2 \%$ of the patients had been hospitalized in the last year due to decompensated IC. Most of the participants were former smokers (57.7\%), did not consume alcohol (82.9\%) and were sedentary $(95.1 \%)$.

Improvement was observed in knowledge about IC after the nursing intervention during home visits, as shown in Figure 1. On average, the mean percentage of knowledge about IC during the first home visit was $64 \pm 18.2 \%$. After nursing intervention, during the 
second home visit, the mean percentage of knowledge increased to $70.8 \pm 16.9 \%$, showing a significant improvement in learning with regard to IC $(p=0.020)$.

Figure 1. Percentage of the average knowledge of patients with regard to IC during the first and second home visits. Porto Alegre - RS, 2011. * Paired t-test.

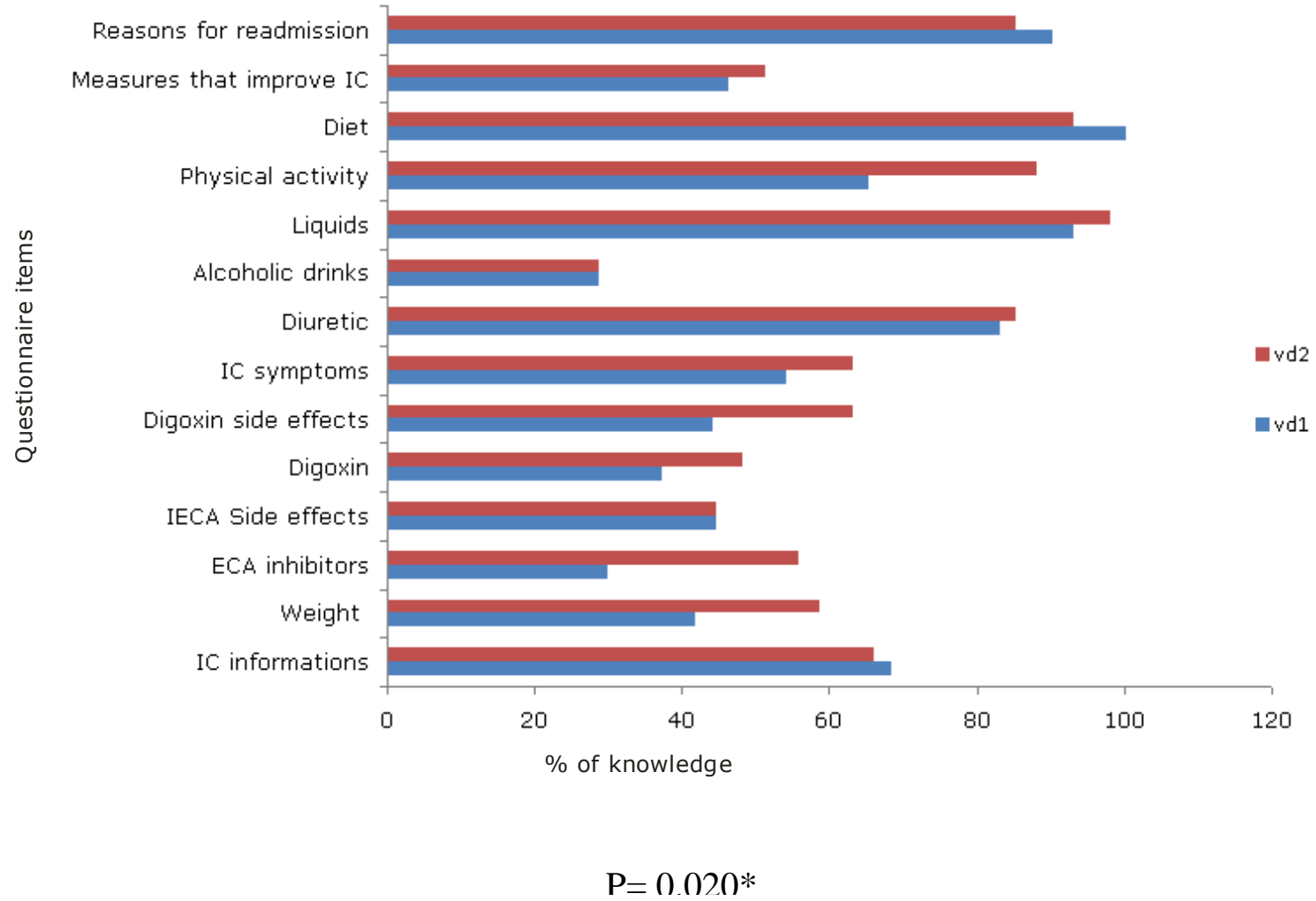

VD1: first home visit; VD2: second home visit

During the home visits the patients demonstrated that they had an increased knowledge of symptoms of IC, such as the diuretic effect, foods containing liquid and salt, and reasons that led to their hospitalization. When comparing the extent of the knowledge gain before and after the nursing intervention, there was a statistically significant difference only in terms of physical activity $(P=0.035)$, as shown in Figure 2 . 
Figure 2. Questionnaire items relating to knowledge about IC. Porto Alegre - RS, 2011.

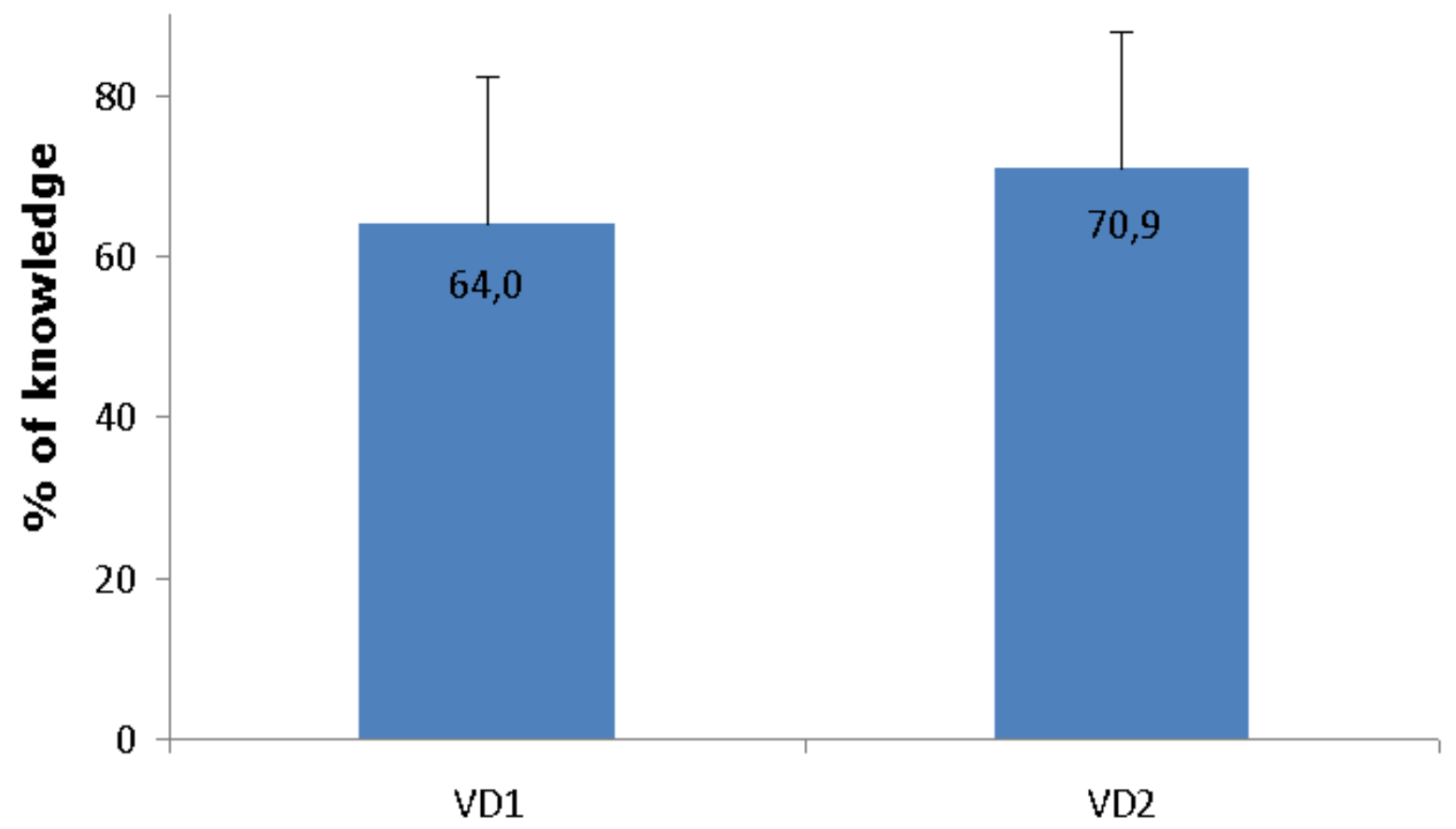

There was no significant correlation between the increase in the percentage of average knowledge acquired in VD1 and VD2 and IC and IC time ( $r s=0.23, P=0.152)$, and, also, between schooling and the increase in the percentage of average knowledge ( $r s=0.23, P$ $=0.153)$.

\section{DISCUSSION}

This study assessed the knowledge of the patients with IC about their disease and selfcare, before and after nursing intervention in the form of homecare. It is believed that adherence to the treatment of IC depends on the knowledge and understanding on the part of the patients and their families, as part of an ongoing process of education ${ }^{(6)}$.

It is observed, in this study, that patients had a high basal level of knowledge about IC when compared with an American study ${ }^{(4)}$ which assessed the same topic to indicate that the average percentage in terms of the level of knowledge $38.9 \%$ (5.83 hits) on 15 questions. This is considered to be a low level of knowledge about the disease. 
Furthermore, patients showed an improvement in knowledge about IC after the nursing orientation session during the home visits. The nursing intervention benefitted patients by improving their knowledge, whether done through the home visits, by telephone contact or by group orientation. A study of patients with IC who had been hospitalized and were then followed by telephone contact for three months showed significant improvement in knowledge and self-care scores ${ }^{(9)}$.

In this study, among the issues evaluated in terms of knowledge of IC, it was observed that the question of physical activity had a greater number of correct responses on the part of the patients, showing a statistically significant improvement. There were also a greater number of correct answers on questions about weight control, medication, heart failure symptoms, fluid control and measures to improve IC. However, these results were not statistically significant.

It is observed that patients have difficulty in understanding the non-pharmacological treatment of IC, which is essential for optimal treatment. In the study ${ }^{(8)}$ of the validation of the questionnaire about IC for the Brazilian situation, just over half of the patients could answer the question related to weight gain, but one in five patients could not answer how they should restrict salt on a daily basis. This demonstrates that patients still are uncertain about the weight gain from fluid retention and the worsening of IC, as well as salt and fluid restriction ${ }^{(8)}$.

In this study, the strategy used was home visits on the part of specialist nurses, which shows up as a facilitating tool for a rapprochement between the health professional and the patient and his or her family. A study in Spain involving IC patients who received home interventions by nurses, found that after one year, the rates of return to hospital, mortality rates and the quality of life ${ }^{(10)}$ decreased.

\section{CONCLUSION}

The home care performed by nurse specialists led to a significant improvement with regard to knowledge of the disease and self-care on the part of patients with heart failure. 


\section{REFERENCES}

1. Sociedade Brasileira de Cardiologia. III Diretriz Brasileira de Insuficiência Cardíaca Crônica. Arq Bras Cardiol. 2009; 93 (1supl. 1): 1-71.

2. Rabelo ER, Aliti GB, Domingues FB, Ruschel KB, Brun AO. O que ensinar aos pacientes com insuficiência cardíaca e por quê: o papel dos enfermeiros em clínicas de insuficiência cardíaca. Rev Latino-Am Enfermagem [serial in the Internet]. 2007 Feb [cited 2012 June 23]; 15(1): 165-70. Available from: http://www.scielo.br/scielo.php?script=sci arttext\&pid=S0104$11692007000100024 \&$ Ing $=$ en

3. Linhares JC, Aliti GB, Castro RA, Rabelo ER. Prescrição e realização do manejo não farmacológico para pacientes com insuficiência cardíaca descompensada, internados em emergência de hospital universitário. Rev Latino-Am Enfermagem. 2010; 18(6):1145-51.

4. Artinian NT, Magnan M, Christian W, Lange PM. What do patients know about their heart failure? Appl Nurs Res. 2002; 15(4): 200-8.

5. Corrêa L, Santos I, Albuquerque D. Nursing assessment: Research/Care through the sensible listening in the heart failure clinic. Online braz $j$ nurs [serial in the Internet]. 2008 Mar [cited 2011 November 16]; 7(1). Available from: http://www.objnursing.uff.br/index.php/nursing/article/view/j.1676-4285.2008.1066

6. Aliti GB, Rabelo ER, Domingues FB, Clausell N. Cenários de educação para o manejo de pacientes com insuficiência cardíaca. Rev Latino-Am Enfermagem. 2007; 15(2): 344-9.

7. Rabelo E, Aliti G, Domingues F, Ruschel K, Brun A, Gonzalez S. Impact of nursing systematic education on disease knowledge and self-care at a heart failure clinic in Brazil: prospective an interventional study. Online braz $\mathrm{j}$ nurs [serial in the Internet]. 2007 Nov [Cited 2011 November 29]; 6(3). Available from: http://www.objnursing.uff.br/index.php/nursing/article/view/1039

8. Rabelo ER, Mantovani VM, Aliti GB, Domingues FB. Adaptação transcultural e validação de um questionário de conhecimento da doença e autocuidado, para uma amostra da população brasileira de pacientes com insuficiência cardíaca. Rev LatinoAm Enfermagem [serial in the internet]. mar 2011 [cited 2011 June 15];19(2). Available from: www.eerp.usp.br/rlae.

9. Domingues FB, Clausell N, Aliti GB, Dominguez DR, Rabelo ER. Educação e monitorização por telefone de pacientes com insuficiência cardíaca: ensaio clínico randomizado. Arq Bras Cardiol. 2011; 96(3): 233-9.

10. Brotons C, Falces C, Alegre J, Ballarin E, Casanoas J, Catá T, et al. Randomized clinical trial of the effectiveness of a home-based intervention in patients with heart failure: the IC-DOM study. Rev Esp Cardiol. 2009; 62(4):400-8.

\section{Participation Authors' in the research}

Daiane Bertuzzi: Conception and design, data collection, interpretation and analysis, writing the article, final approval of the article.

Emiliane Nogueira de Souza: Conception and design, data collection, interpretation and analysis, writing the article, critical revision of the article, final approval of the article.

Maria Antonieta Moraes: Conception and design, critical revision of the article, final approval of the article.

Cláudia Mussi: Conception and design, data collection, interpretation and analysis, final approval of the article. 
Eneida Rejane Rabelo: Conception and design, critical revision of the article, final approval of the article.

Received: 20/01/2012

Approved: 05/07/2012 